\title{
Paraphenylenediamine hair dyeing nephropathy: a case report and review of literature
}

\begin{abstract}
Hair dye poisoning has been emerging as one of the important causes of intentional or non-intentional poisoning all over the world. Modern hair dyes contain paraphenylenediamine and a host of other chemicals that can cause rhabdomyolysis, laryngeal edema, acute kidney injury, severe metabolic acidosis and acute renal failure. Intervention at the right time has been shown to improve the outcome. In here, we report a case of acute kidney injury following inhalation of hair dye during hairstyle session.
\end{abstract}

Keywords: hair dye poisoning, paraphenelyn diamin, acute interstitial nephritis, acute renal failure, chronic renal failure
Volume 6 Issue 5 - 2018

\author{
Ahmed Akl, ${ }^{1,2}$ Raha MAlturki' \\ 'Dr. Soliman Fakeeh Hospital, Saudi Arabia \\ ${ }^{2}$ Urology \& Nephrology Center, Mansoura University, Egypt \\ Correspondence: Ahmed Akl, ISN Educational Ambassador, \\ Consultant of Nephrology \& Transplantation, Urology \& \\ Nephrology Center, Mansoura University, Egypt, \\ Emailaiakl200I@yahoo.com
}

Received: August 29, 2018 | Published: September 27, 2018

\section{Introduction}

Para-phenylene-diamine (PPD), this is an organ compound. This is a derivative of aniline, is a white solid but became darker on air oxidation. It is broadly used in the composition of various types of commercially available hair dye formulations. ${ }^{1,2}$ HENNA (the leaves of lawsonia alba) is mixed with PPD to accelerate the process of dyeing and to darken its color in many regions around the world. It is not only applied to color hair but as well for body tattooing. ${ }^{3-7}$ PPD may evoke local and/or systemic toxic effects either when utilized topically, inhalated and/or ingested. Locally, it can result in allergic dermatitis, asthmatic bronchitis, joint pain and stiffness, conjunctivitis or even loss of vision when applied to the eyes in vulnerable individuals. ${ }^{8}$ PPD is poisonous when ingested and the higher the dose the worse is the outcome. The lethal dose of PPD is not known; estimates vary from $7-10 \mathrm{~g} .{ }^{9}$ A large dose will lead to death within the first 6-24 hours of ingestion from angioneurotic edema or cardiac arrhythmia. ${ }^{10}$ If rhabdomyolysis or renal failure develops, mortality rate reaches $31 \% .{ }^{11}$ Smaller doses, or if the patient vomits most of the dye, may present as angioneurotic edema with no further sequelae. A moderate dose will cause acute renal failure within the first week. ${ }^{6}$ We are presenting this case to highlight the importance of adequate history taking, early recognition of the hair dye poisoning symptoms and prompt management of its toxicities.

\section{Case report}

A 32-year-old female patient, with no previous medical history, went to her hairdresser for a new look 4 days ago. The keratin-based hair dye had a sting odor and the room was not well ventilated, she inhalated the odor for more than two hours. Following the hairdressing session, she developed epigastric pain, persistent vomiting for 3 days with no improvement to anti-emetics. While investigating the underlying cause of gastric upsets, her serum creatinine was accidentally discovered to be high $6.4 \mathrm{mg} / \mathrm{dl}$, renal ultrasound revealed normal size both kidneys, hyperechogenic parenchyma grade 1 with no back pressure. On examination, patient complained of breathing discomfort, her blood pressure was normal $110 / 70 \mathrm{mmHg}$, pulse 100 Beat $/ \mathrm{min}$, chest had scattered wheezes otherwise clear to auscultation, abdomen was lax, soft, with epigastric tenderness, with no oedema lower limb. Serum creatinine was $7.4 \mathrm{mg} / \mathrm{dl}$, BUN $38.5 \mathrm{mg} / \mathrm{dl}$ (Figure 1) (Figure 2) with metabolic acidosis, serum Bicarb 18 dropping to $15 \mathrm{mmol} / 1$, normal potassium, sodium levels, drop of hemoglobin $2 \mathrm{gms}$ in 24 hours, leukocytosis and urine analysis (Figure 3) (Figure 4) shows no proteinuria, no hematuria, no myoglobinurea, amorphous urate, all immunological workup was normal (Table 1). Improvement of pre-renal hypovolemia and metabolic acidosis was achieved by fluid resuscitation utilizing $77 \mathrm{meq}$ sodium bicarbonate mixed in one liter half normal saline at rate of $2 \mathrm{ml} / \mathrm{kg} / \mathrm{hr}$. Twenty-four hours later, no improvement in renal function was noticed and serum creatinine rose to $8.1 \mathrm{mg} / \mathrm{dl}$, BUN 39.9, drop of hemoglobin from 12 to $10 \mathrm{~g} / 1$ (2gm), rapid jump of serum uric acid from 6.4 to $9.09 \mathrm{mg} / \mathrm{dl}$ with normal urine volume and analysis. Patient started to complain from shortness of breath but no vomiting. By exclusion of rhabdomylosis (clear urine with satisfactory flow rate), a clear picture of intoxication with bronchitis, pneumonitis, progressive renal failure (interstial nephritis) was settled up and pulse of methylprednisolone 500mg IV per day for 5 days was given. Rapid improvement of renal function with drop of serum creatinine for more than $1.5 \mathrm{mg} / \mathrm{dl}$ per day and patient was discharged with serum creatinine $2.4 \mathrm{mg} / \mathrm{dl}$, BUN $56 \mathrm{mg}$ / $\mathrm{dl}$ (Figure 1) (Figure 2). Patient continued on oral prednisolone $60 \mathrm{mg}$ per day with plan of weaning of steroids in two weeks. At last follow up, she enjoyed normal renal function with serum creatinine $0.69 \mathrm{mg} /$ $\mathrm{dl}$, BUN $8.98 \mathrm{mg} / \mathrm{dl}$, uric acid $3.9 \mathrm{mg} / \mathrm{dl}$ with satisfactory urine output.

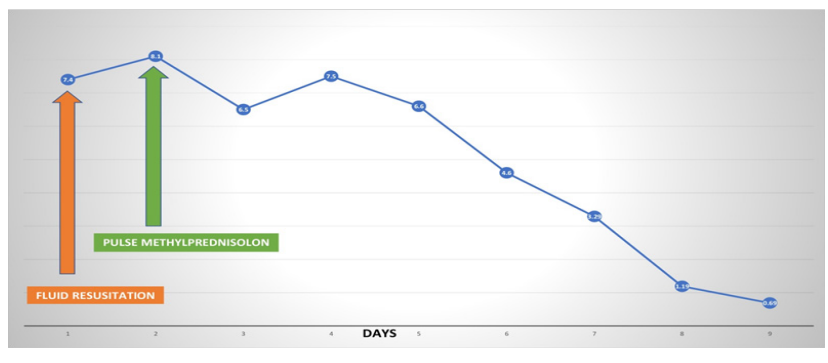

Figure I Patient daily serum creatinine results during treatment 


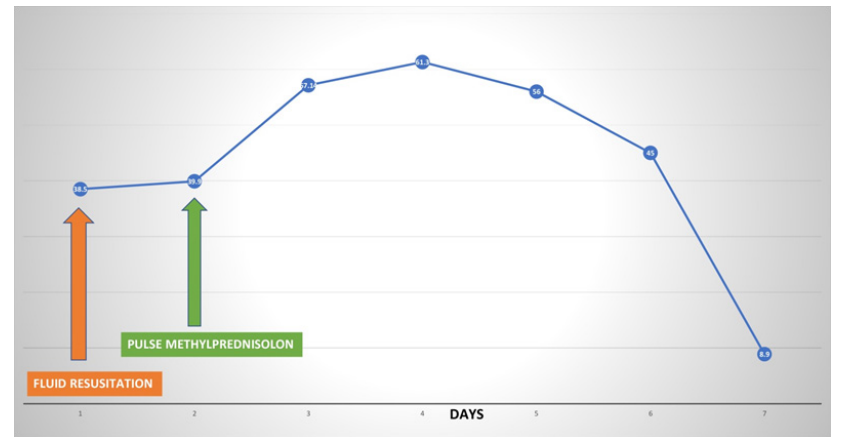

Figure 2 Patient daily serum BUN (Blood urea Nitrogen) results during treatment.

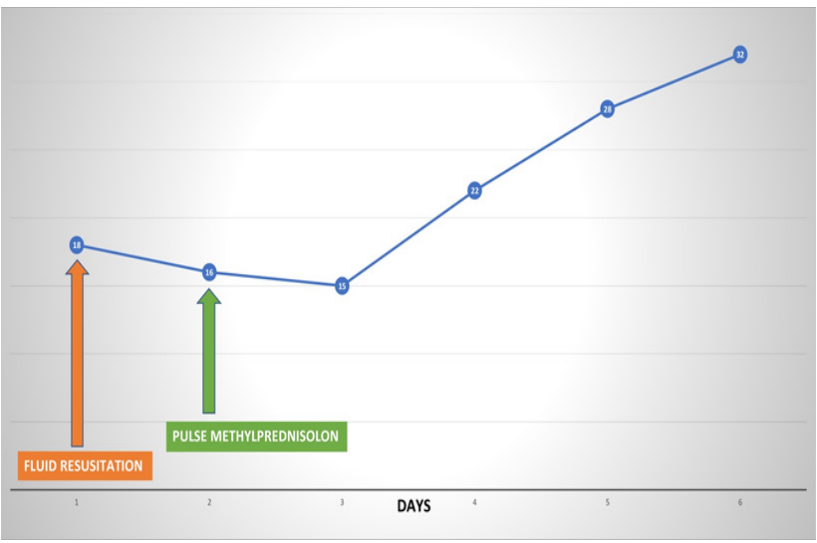

Figure 3 Patient daily serum Bicarbonate results during treatment.

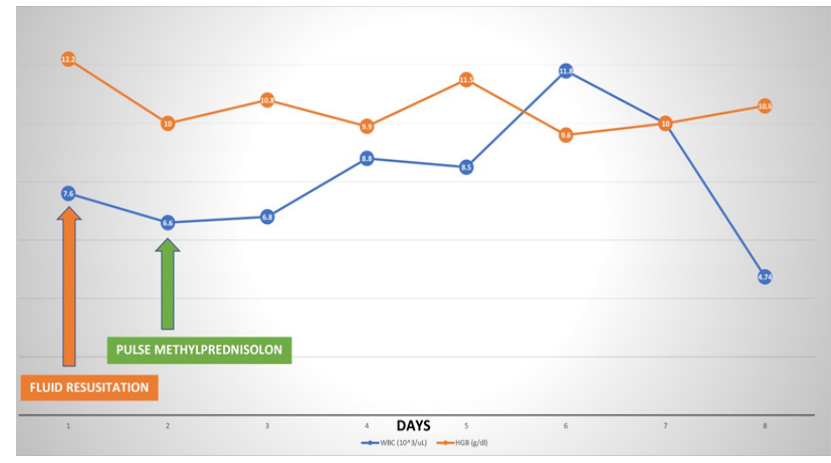

Figure 4 Patient daily Hemoglobin and leukocytic counts results during treatment.

Table I Patient laboratory data on day of admission

\begin{tabular}{ll}
\hline Test & Results \\
\hline Biochemical & \\
Serum Creatinine & $7.4(\mathrm{mg} / \mathrm{dl})$ \\
BUN & $38.5(\mathrm{mg} / \mathrm{dl})$ \\
CRP & $31.5(\mathrm{mg} / \mathrm{dl})$ \\
Uric Acid & $6.42(\mathrm{mg} / \mathrm{dl})$ \\
$\mathrm{HCO}_{3}$ & $18(\mathrm{mmol} / \mathrm{l})$ \\
\hline
\end{tabular}

\begin{tabular}{ll}
\hline Test & Results \\
\hline NA & $134(\mathrm{mmol} / \mathrm{l})$ \\
\hline $\mathrm{K}$ & $4.6(\mathrm{mmol} / \mathrm{l})$ \\
$\begin{array}{l}\text { Immunological } \\
\text { biomarkers }\end{array}$ & \\
\hline Rheumatoid Factor & Negative \\
$\begin{array}{l}\text { Complement 4 (C4) } \\
\text { Complement 3 (C3) }\end{array}$ & Normal \\
$\begin{array}{l}\text { Anti-Nuclear } \\
\text { Antibodies }\end{array}$ & $5.7 \quad$ (negative $<20)$ \\
$\begin{array}{l}\text { C-ANCA -PR3 } \\
\text { P-ANCA -MPO }\end{array}$ & $2.1 \quad$ (negative <20) \\
$\begin{array}{l}\text { Viral serology } \\
\text { Hepatitis B Surface }\end{array}$ & $0.34 \quad$ (negative $<20)$ \\
$\begin{array}{l}\text { Antigen (Quantitative) } \\
\text { HIV-Antigen-Antibody } \\
\text { (Combo) }\end{array}$ & $0.08 \quad$ (Non-reactive) \\
$\begin{array}{l}\text { Hepatitis CVirus } \\
\text { Antibody (Total) }\end{array}$ & $0.06 \quad$ (Non-reactive) \\
\hline
\end{tabular}

\section{Discussion}

PPD is a coal-tar derivative, it is not toxic by its nature but upon oxidation several metabolites and intermediates are released in a complex reaction. The most identifiable allergic, mutagenic and highly toxic metabolite is called Bondrowski. ${ }^{2}$

PPD is a product used mainly in cosmetology so the percentage of affected females $(77 \%)$ is more than males $(23 \%) .{ }^{12}$ First documented case of PPD-toxicity was from North of England at 1924, in a hairdresser who was complaining from infrequent attacks of seizures, was suspected as case of either arsenic or lead poisoning as it was reported cases of contaminated beers with arsenic at that time. His fingers were painted with dark dye as he was not used to wear gloves during dyeing the hair of his customers. Samples from the dye was sent to laboratory and revealed para-phenylene-diamine. ${ }^{10} \mathrm{PPD}$ found to be highly absorbed following skin contact. ${ }^{8}$ Several reported cases of acute kidney injuries, two patients were reported in $1982,{ }^{13} 5$ children were put on peritoneal-dialysis. ${ }^{5}$ Largest series was reported from Sudan, 31 Sudanese children with PPD-toxicity. Hand tattooing with HENNA mixed with PPD lead to life threatening anaphylaxis, pulmonary oedema in an Arab lady. Series of reported 18 patients, four had been died from suffocation after acute upper airway obstruction, acute kidney injury and sudden cardiac arrest. ${ }^{6}$

Severity of PPD-toxicity depends on the dose delivered to the body, larger the dose associated with angioedema, more aggressive symptoms and higher mortality. ${ }^{2,5,6}$ Angioedema is a well-recognized non-pitting edema involving the deeper layers of the skin, subcutaneous tissue, and mucosa that can lead to life threatening airway obstruction. ${ }^{6,14}$

Symptoms of PPD-toxicity usually start early within 4-6 hours post ingestion and includes a variety of non-specific but progressive presentation ranging from early phase: burning sensation of throat, mouth, vomiting, abdominal pain reaching to respiratory distress, 
pulmonary oedema and may be suffocation. Late phase includes intravascular hemolysis, rhabdomyolysis, acute kidney injury and cardiac arrhythmia.

Toxicity may cause leakage of calcium from the smooth endoplasmic reticulum leading to irreversible muscular contraction and fever. The clinical picture may mimic and confused clinically with seizure attacks. This may lead to muscular structural damage and rhabdomyolysis. ${ }^{15,16}$ As well, it is associated with signs of intravascular hemolysis; anemia, haemoglobinaemia, haemoglobinuria and metabolic acidosis. Early correction of metabolic acidosis and good hydration with half normal saline and sodium bicarbonate infusion has shown beneficial in reverting rhabdomyolysis and improving acute kidney injury. In our case we had no signs suggesting rhabdomyolysis as urine analysis was normal in colour, no myoglobin.

Experimentally, in guinea pigs daily application of PPD on the skin resulted in high histamine level as a part of hypersensitive reaction. ${ }^{14}$ Histopathological tissue damage has been attributed in guinea pigs to the release of free-radical agents in PPD-toxicity. ${ }^{14} \mathrm{~N}$-methylated PPD induced necrosis of smooth and skeletal myocytes in rats. ${ }^{17}$ In humans, autopsies revealed scattered coagulation necrosis of skeletal myocytes. ${ }^{2,18}$

Acute kidney injury in PPD-toxicity has several mechanisms: initially; direct toxic action of PPD or its metabolites on the renal parenchyma. Its high filtration rate and after oxidation converted to nephrotoxic agents specially quinone-diamine. Then, indirect through the Hemolysis, met-hemoglobinemia and myoglobin casts leading to tubular damage. ${ }^{1,2}$ In humans, autopsy of patients revealed combined renal tubular occlusion by myoglobin casts and acute tubular necrosis. ${ }^{18,19}$

Currently, no specific antidote or approach for handling patients suffering PPD toxicity. The major key of success is early diagnosis of PPD-toxicity by taking good medical history. Then once suspected supportive measures to start immediately, depending on the state of presentation. Impending angioneurotic oedema needs urgent steroids and antihistamine therapy. In more serious cases urgent tracheostomy to secure airway patency. ${ }^{6}$ Rhabdomyolysis needs correction of metabolic acidosis, alkaline diuresis and good fluid management. If acute kidney injury develops and not responding to fluid therapy and steroids, supportive renal replacement therapy is lifesaving until kidney function recovers. Plasma exchange has been reported to show benefit in treating PPD-toxicity. ${ }^{11}$

Acute kidney injury following hair dyeing or body tattooing should remind us with PPD intoxication. Awareness of PPD-toxicity will lead to early diagnosis and proper management. Our recommendations include: avoidance of inhalation of hair dye fumes, good ventilation of hairstyle facilities and always utilizing gloves when handling hair dyes.

\section{Acknowledgements}

None.

\section{Conflict of interest}

Author declares there is no conflict of interest in publishing the article.

\section{References}

1. Chugh KS, Malik GH, Singhal PC. Acute renal failure following paraphenylene diamine [hair dye] poisoning: report of two cases. $J$ Med. 1982;13(1-2):131-137.

2. Ashraf W, Dawling S, Farrow LJ. Systemic paraphenylenediamine (PPD) poisoning: a case report and review. Hum Exp Toxicol. 1994;13(3):167-170.

3. Läuchli S1, Lautenschlager S. Contact dermatitis after temporary henna tattoos--an increasing phenomenon. Swiss Med Wkly. 2001;131(1314):199-202.

4. Abdulla KA1, Davidson NM. A woman who collapsed after painting her soles. Lancet. 1996;348(9028):658.

5. Sir Hashim M1, Hamza YO, Yahia B, et al. Poisoning from henna dye and para-phenylenediamine mixtures in children in Khartoum. Ann Trop Paediatr. 1992;12(1):3-6.

6. Umair SF, Amin I, Urrehman A. Hair Dye poisoning: "An early intervention". Pak J Med Sci. 2018;34(1):230-232.

7. Ashar A. Acute angioedema in paraphenylenediamine poisoning. J Pak Med Assoc. 2003;53(3):120-122.

8. Mathur AK1, Gupta BN, Narang S, et al. Biochemical and histopathological changes following dermal exposure to paraphenylene diamine in guinea pigs. J Appl Toxicol. 1990;10(5):383-386.

9. Singla S, Miglani S, Lal AK, et al. Para-penylenediamine (PPD) Poisoning. JIACM. 2005;6(3):236-238.

10. Nott HW. Systemic Poisoning by Hair Dye. $\mathrm{Br}$ Med J. 1924;1(3297):421-422.

11. Rund D, Schaap T, Da'as N, et al. Plasma exchange as treatment for Lawsone (henna) intoxication. J Clin Apher. 2007;22(4):243-5.

12. Filali A, Semlali İ, Ottaviano V, et al. A retrospective study of acute systemic poisoning of paraphenylenediamine (occidental takawt) in Morocco. AJTCAM. 2006;3(1):142-149.

13. Chugh KS, Malik GH, Singhal PC. Acute renal failure following paraphenylene diamine [hair dye] poisoning: report of two cases. $J$ Med. 1982;13(1-2):131-137.

14. Barna JS, Frable MA. Life-threatening angioedema. Otolaryngol Head Neck Surg. 1990;103(5 ( Pt 1)):795-798.

15. Yabe $\mathrm{K}$. The effect of a p-phenylenediamine containing hair dye on the $\mathrm{Ca} 2+$ mobilization in the chemically skinned skeletal muscle of the rat. Nihon Hoigaku Zasshi. 1992;46(2):132-140.

16. Averbukh Z, Modai D, Leonov Y, et al. Rhabdomyolysis and acute renal failure induced by paraphenylenediamine. Hum Toxicol. 1989;8(5):345-8.

17. R Munday, E Manns, EA Fowke, et al. Muscle necrosis by N-methylated p-phenylenediamines in rats: Structure-activity relationships and correlation with free-radical production in vitro. Toxicology. 1989;57(3):303-314.

18. Saito K, Murai T, Yabe $K$, et al. Rhabdomyolysis due to paraphenylenediamine (hair dye)--report of an autopsy case. Nihon Hoigaku Zasshi. 1990;44(5-6):469-74.

19. Bourquia A, Jabrane AJ, Ramdani B, et al. Systemic toxicity of paraphenylenediamine. 4 cases. Presse Med. 1988;17(35):1798-1800. 